\title{
Periferias genéricas: la crónica y el documental frente a las urbanizaciones privadas
}

Genre Periphery: chronicles and documentary films on gated communities

\section{MERCEDES ALONSO}

UNIVERSIDAD DE BUENOS AIRES · meralonsa@gmail.com

Profesora y Licenciada en Letras por la Universidad de Buenos Aires donde cursa sus estudios de Doctorado sobre Literatura Latinoamericana contemporánea. Participa en grupos de investigación y escribe y publica dentro de las áreas de las literaturas comparadas y del cine de América Latina.

RECIBIDO: 19 DE SEPTIEMBRE DE 2015

DOI: $10.7203 /$ KAM.6.6972

ACEPTADO: 1 DE DICIEMBRE DE 2015

ISSN: 2340-1869

Resumen: En la Argentina de la primera década del siglo XXI, las urbanizaciones cerradas fueron escenario de diversas obras de ficción literaria y fílmica que parecían hacer eco a la atención mediática que reclamaban tanto la consolidación del fenómeno como una serie de hechos policiales de amplia repercusión. Sin embargo, resultaron prácticamente ausentes de los géneros no-ficcionales del cine y la literatura tradicionalmente enfocados a la representación de lo marginal. Ese virtual vacío llama la atención sobre el documental La ciudad que huye (2006) de Lucrecia Martel y la crónica Mundo privado. Historias de vida en countries, barrios privados y ciudades cerradas (2007) de Patricia Rojas. Por su singularidad, los dos permiten pensar no solo las posibilidades narrativas del barrio privado sino las configuraciones genéricas y los imaginarios que se les asocian y que parecen entrar en contradicción con estos espacios vinculados al privilegio.

Palabras claves: No ficción, barrios cerrados, literatura y cine.
Abstract: In the first decade of the XXI century Argentina, gated communities were the setting of a wide number of filmic and literary fictions that seemed to echo the attention the media was giving to the phenomenon due to its consolidation and the impact of a series of crimes that took place in them. However, they remained absent from non-fiction both in literature and film, genres traditionally concerned with the representation of the margin. This virtual representational void calls attention to the documentary short La ciudad que huye (Lucrecia Martel, 2006) and Mundo privado. Historias de vida en countries, barrios privados y ciudades cerradas (Patricia Rojas, 2007). These works uniqueness enables us to ponder on the spaces narrative possibilities, on non-fiction as genre and on its usual themes and subjects that seem to reject these privileged scenarios.

Palabras claves: Non-fiction, Gated communities, Literature and Film. 
En la Argentina de principios del siglo XXI, los countries y barrios privados, esos enclaves de riqueza en zonas apartadas de las grandes ciudades pero protegidos y aislados de las otras caras de la periferia, han sido objeto de numerosas ficciones. Un poco por la consolidación de esos espacios y las formas de vida que les son propias, otro poco por los hechos delictivos que los tuvieron por escenario en el período, esos espacios que solemos asociar a la década de 1990, demonizada como reino neoliberal de la ostentación y la especulación inmobiliaria, vuelven a aparecer en medio de una década que trata de definirse como todo lo contrario. Las viudas de los jueves (2006), novela de Claudia Piñeiro que gira en torno a un crimen en un country y que fue llevada al cine en 2009 por Marcelo Piñeyro, es, por su éxito, un punto de partida para pensar una serie más amplia. Sin ir más lejos, la sucesión novela-película continuó, aunque con mucha menos repercusión, con la novela Betibú (2012), de la misma autora, y su respectiva película, esta vez dirigida por Miguel Cohen en 2014. En los dos casos, el country o barrio privado resultaba terreno fértil para jugar con la contradicción de intrigas policiales en espacios supuestamente seguros y alejados de los males urbanos.

El espacio controlado parece invitar a la ficción. Lo señalan Stéphane Degoutin y Gwenola Wagon, quienes proponen que la "gated community" - equivalente global de las denominaciones locales - es un marco natural para la ficción porque permite revelar aspectos sociales en un territorio bien delimitado a la vez que dialoga con motivos universales de segregación espacial como el arca de Noé, la isla o el cuarto cerrado. Algo similar nota Marta Muñoz Aunión (2013), quien agrega un elemento central para estos textos: no solo hay riqueza narrativa en el barrio cerrado sino una tensión intrínseca que es la que aparece en las ficciones argentinas. Los films Cara de queso (2006) de Ariel Winograd y Una semana solos (2007) de Celina Murga, aunque genéricamente distantes de los policiales de Piñeiro, no hacen sino explotar el aislamiento como un equilibrio muy delicado que puede ser puesto en jaque por episodios infantiles - una agresión, algunos episodios vandálicos- que minan la tranquilidad de sus habitantes y revelan la trama precaria que la sostiene. El conflicto en el paraíso es una ficción recurrente. No es otra cosa la novela De tripas corazón (2010), de Mercedes Reincke, que explora la trama de secretos que recorren la vida del country en la voz de dos mujeres que lo habitan.

A pesar de su fertilidad ficcional y de la relevancia mediática de que fueron objeto para la misma época a partir de dos casos policiales de amplísima repercusión - el asesinato de María Marta García Belsunce en el barrio El carmel de Buenos Aires en 2002 y de Nora Dalmasso en el country Villa Golf de Río Cuarto, Córdoba, en 2006-, los countries y barrios privados parecen prácticamente ausentes de los géneros no-ficcionales del cine y la literatura. Ese virtual vacío hace más interesante la indagación en los 
que sí existen: el corto documental La ciudad que huye $(2006)^{1}$ de Lucrecia Martel y la crónica Mundo privado. Historias de vida en countries, barrios privados y ciudades cerradas (2007) de Patricia Rojas ${ }^{2}$. Por su singularidad, los dos permiten pensar no solo las posibilidades narrativas del barrio privado sino las configuraciones genéricas y los imaginarios que se les asocian y que parecen entrar en contradicción con estos espacios.

En el caso de la crónica-testimonio, la centralización del hábitat de clases altas y medias-altas en busca de seguridad y protección frente a sociedades en crisis supone el abandono de los personajes favoritos del género - de clases bajas, subalternos, marginales según el momento y los marcos teóricospara focalizarse en su contrario, los privilegiados. Esos sujetos abren la puerta a un tema marginal al género; un espacio ubicado en la periferia urbana aunque con un signo contrario a los usualmente explorados. El viraje en los temas usuales de las crónicas es anterior. En 2005, Hernán Iglesias Illia había ganado el Premio Crónica de Planeta/Seix Barral con un proyecto que luego se publicaría como Golden Boys. Vivir en los mercados (2006) sobre los economistas argentinos en Wall Street. Los otros finalistas de esa primera edición del premio proponían un cambio similar. Carlos Paredes Rojas (Perú), en El código La Pinchi, trabajaba sobre una mujer cercana a Vladimiro Montesinos, personaje crucial del fujimorismo, y Joaquín Botero (Colombia), en El jardín de Chelsea, sobre un inmigrante feliz en un barrio lujoso de Nueva York. Esa primera edición del premio es un hito en tanto parece querer confrontar con los que históricamente han sido los objetos y los objetivos del género. Sin entrar en discusiones sobre posibles antecedentes, el surgimiento del relato testimonial en la década de 1960 está atravesado por la política y por la capacidad del género de hacerse cargo de lo marginal en términos de clase, de etnia, de género, etc. Incluso en un momento más cercano al presente, Mónica Bernabé (2006) cierra la lista de momentos clave del género no ficcional - crónicas de indias, modernismo, Walsh-con el fin del siglo XX, en el que su función sería rescatar la memoria colectiva frente a la pérdida de ciudadanía de amplios sectores sociales. Para Juan Duchesne Winter (1992), ese rasgo de subalternidad o marginalidad del testimoniante es parte de la definición de un género que busca en ellos un discurso alternativo, opuesto a los dominantes.

Con el documental ocurre algo similar. Sin entrar en una historia que podría resultar inabarcable dada su amplitud y diversidad, resulta significativo que en la producción cinematográfica argentina

${ }^{1}$ El documental fue realizado para una muestra de la Facultad de Diseño, Arquitectura y Urbanismo de la Universidad de Buenos Aires y cuenta con la colaboración de especialistas del urbanismo, la sociología, etc.

${ }^{2}$ También en 2007 apareció el libro Vidas perfectas. Los countries por dentro de Carla Castelo. Además de haber tenido una repercusión casi nula, el texto queda fuera de este trabajo porque si bien establece una filiación con la crónica y el testimonio, el predominio de la voz autoral lo aleja de las configuraciones genéricas que se consideran aquí. 
contemporánea a La ciudad que huye, la vertiente del género que se ha consagrado a la crónica social esto es, excluyendo el giro subjetivo que también se ha vuelto una opción válida- ha preferido la exposición de los márgenes sociales. Después de la crisis de 2001, dice Jens Andermann, el documental participa de una "explosión de lo real" (2015: 162) que expone su saldo negativo. En principio, el de Martel no se aparta de ese modelo en la medida en que el fenómeno de expansión de los barrios cerrados y countries aparece fuertemente vinculado con la paralela expansión de los bolsones de pobreza. Además de compartir el espacio periférico, los dos son consecuencias de la crisis; como señala Maristella Svampa, la nueva periferia se reparte violentamente entre "ciudades fortificadas" y "ghettos pobres" (2006: 100). Sin embargo, el foco del documental son las primeras y no los segundos; son su historia, su lógica y su imagen las que construyen el relato.

Lo que el texto de Patricia Rojas y el documental de Martel invitan a repensar es la definición misma de los géneros, qué otros objetos de indagación son posibles a partir de las voces y las imágenes del privilegio, qué otros objetivos aparecen cuando la representación recae sobre sectores dominantes. Las ficciones portan una enseñanza, al menos para la lectura que pretendo organizar, puesto que en los dos casos el espacio cerrado que es objeto de la representación y no solo paisaje de fondo le da forma a los materiales, produce una marca en el género y en los principios constructivos de las obras. La frontera y el viaje definen el acercamiento de la cronista y los documentalistas a esos lugares alejados y aislados de la urbe, son también parte importante de la representación y problematización del espacio y son, por lo tanto, las escenas que estructuran este análisis.

\section{Fronteras uniformes}

El cerramiento perimetral y la seguridad privada son los únicos elementos que, según Svampa (2006), unifican a los countries, barrios privados, barrios de chacras, ciudades cerradas y condominios que componen la oferta de espacios residenciales privatizados. El territorio se define por el contorno, lo que lo cerca y lo rodea como medida defensiva contra lo que lo cerca y lo rodea un poco más allá, el resto de la periferia. Estas particulares fronteras artificiales son también el acceso para los habitantes que las cruzan todos los días y para quienes se acercan a explorar. La marca sobre el espacio y sobre el itinerario del que llega es tan fuerte que ese límite/entrada determina la mirada de Rojas y Martel. El encuentro con el límite es la primera y definitoria experiencia del espacio.

Mundo privado empieza con un doble ingreso autobiográfico, primero al country Dalvian, en Mendoza, para visitar a una tía en la década de 1980 y después la primera visita a Nordelta, en Tigre, como parte de la investigación que conduce al libro. El contraste queda tácito pero ubica el objeto en la periferia de la Ciudad de Buenos Aires y en el presente, más Nordelta que Dalvian. La primera entrada 
es, sin embargo, tímida. Rojas dice que todavía no habla con ningún vecino pero que sí repara en los albañiles, empleados y mucamas que también ocupan ese mundo. Aunque los límites perimetrales no son aún protagonistas de su relato, la entrada de Rojas es a través de otra frontera, la humana, definida por la actividad que los ocupa en la crónica: irse, salir. "A partir de las 5 de la tarde se produce una procesión de gente que trabaja en la construcción", las empleadas "suelen esperar en la puerta de cada barrio a las combis blancas", "los sábados al mediodía se produce la segunda procesión: salen las mucamas" (2006: 22). Los diferentes tipos de empleados son una figura liminar en el country, están adentro pero portan una extranjería que los vuelve objeto de vigilancia (Svampa, 2006) y, como el perímetro, conectan el adentro y el afuera con sus desplazamientos. El comienzo del texto a través de estos sujetos-frontera define el lugar de la cronista que es, también, una viajera entre dos espacios, una forma específica de ocupar el lugar de mediadora (Amar Sánchez, 2008) o intermediaria (Ford, 1987) que propone el género: "Fue un viaje que incluyó atravesar barreras y molinetes para llegar hasta los jóvenes que viven en estos espacios cerrados" (Rojas, 2006: 35).

La primera imagen de La ciudad que huye es también una frontera doble: un guardia que impide el acceso de los documentalistas desde atrás de una reja. Este plano es clave porque al definir las condiciones de acceso inscribe las condiciones de producción en el desarrollo del film. El segmento es también un relato autobiográfico. Las leyendas que corren por la pantalla al mismo tiempo que la imagen de un muro captado desde un auto en movimiento, sin voz en off que las acompañe, cuentan la prehistoria de este documental. "Hace veinte años, buscando locaciones para un corto, conocimos un barrio cerrado" (16"). El rechazo inicial de la idea da lugar a esta recuperación tardía del concepto y de algunas de las imágenes originales. La segunda incursión en el espacio, sin embargo, encuentra la misma imposibilidad de pasar más allá de los límites impuestos, solo que ahora se la revaloriza como objeto de representación. "Estamos filmando carteles y muros" (24") explica la voz de afuera al guardia que pide identificación y cuya imagen se agranda para ocupar toda la pantalla, toda la representación, la única imagen del barrio privado que puede ser mostrada por y para los de afuera. Frente a esa frontera que se afirma en cada intento, la posición de los documentalistas que se inscriben como voces e imágenes fragmentarias en el film es opuesta a la de Rojas: no conectan el afuera con el adentro sino que dan cuenta de la imposibilidad de hacerlo y rodean el objeto, narran la inviolabilidad del perímetro.

Aunque también hay contratiempos en los ingresos, el género testimonial de Rojas obliga a establecer puentes con sujetos de adentro que otorgan el pase. Los accesos que se cierran no son físicos sino de información: con la Federación Argentina de Clubes de Campo no puede hacer entrevistas en persona, solo puede comunicarse por mail o por teléfono, los colegios del barrio Abril resisten todos los acercamientos, una madre de Los Pingüinos pide ver con anticipación el cuestionario que la cronista va a utilizar con los adolescentes. La frontera de silencio parece elaborada específicamente para un género 
que busca indagar en lo que no se dice. Sin embargo, cuando se vuelve inviolable cobra valor testimonial por la dinámica social de exclusividad que muestra al ocultar. Las fronteras físicas, sin embargo, existen y las escenas de entrada definen un espacio marcado por muros, rejas y garitas que caracteriza el viaje y la labor de la cronista. Llevado al plano de la narración escrita y no de las imágenes, el recurso es similar al que Muñoz Aunión (2013) describe en el documental On the safe side: el dispositivo de seguridad, allí la cámara, acá más que nada la garita de entrada con sus respectivos guardias, participa de una representación que se vale de sus dispositivos de vigilancia. Así, Rojas cuenta el ingreso a Nordelta donde es demorada y puede conversar con los empleados en su misma situación; a Tortugas, donde le dan una identificación de "visitante" y le retienen el DNI; a Highland Park, donde los residentes entran con tarjeta magnética mientras los visitantes y empleados, o ella misma, aguardan en una entrada diferente. El ingreso es parte de la historia que se cuenta, del espacio que se describe -las prácticas de seguridad definen, entre otras cosas, la exclusividad de lo que se extiende más allá de la frontera-; la vida cercada se vuelve incluso un tópico de las historias de vida que la cronista recoge, los chicos que no pueden salir sin autorización, el sistema de selección que cada barrio usa para elegir nuevos vecinos, etc. Pero estas escenas de entrada, sobre todo, le da forma a la narración puesto que si a cada barrio le corresponde un capítulo, el cruce de la frontera es ingreso al espacio y organizador textual, principal artificio del montaje que, según Amar Sánchez (2008), define a un género cuyo arte está en la selección y organización de la información.

La imagen producida por los dispositivos de seguridad no está donde se podría esperar en el documental de Martel, que más bien se ocupa de construir una contra-imagen: ver a quienes vigilan, filmar el lugar desde donde los filman, visibilizar el muro que oculta. Vedado el acceso, la representación se llena con otros materiales. El primero es la cuantificación. Los números que acompañan las imágenes y la voz en off dan cuenta del crecimiento de los barrios, sus habitantes, la superficie ocupada. En las antípodas de la humanización testimonial, Martel apela a un discurso y una estética sin personas: números, mapas, imágenes satelitales que organizan el desarrollo del filme como las escenas de entrada en el texto de Rojas. El documental se compone de segmentos que corresponden a diferentes barrios, cada uno identificado con su nombre y una imagen satelital que ocupa el lugar de lo que la cámara no capta del otro lado del muro. El segundo material son las escenas de entrada, o de su imposibilidad: el primer guardia que habla desde atrás de la reja, otro que intercepta la entrada a la urbanización privada Tigre Joven, una escena más completa en la que la imagen de una reja se acompaña de la comunicación de un guardia con otro a través de un handy en la que se escucha el pedido de una autorización que nadie tiene, y una última en la que parece subir la tensión porque aparecen, también, otras personas no identificadas como guardias que relojean a la cámara con fastidio. 
Por último, si la representación de los barrios privados no incluye habitantes, lo que aparece en cambio es otra serie de segmentos intercalados a los que se les coloca la leyenda "Los vecinos de enfrente". Aunque suene amable, se trata de los barrios de clases bajas con los que los countries y barrios privados suelen disputar la periferia. Este "patrón socio espacial" (Svampa, 2006: 15) tan desgarrado como la sociedad que lo produce se visibiliza a través de la extrapolación de un recurso convencional: los espacios se oponen en un plano-contraplano. De un lado el muro, la reja o la enredadera que cerca las urbanizaciones privadas, del otro los barrios pobres donde la ausencia de muros permite ver a los habitantes y sus condiciones de vida. Ninguna imagen los reúne y las tomas que corresponden a cada uno aparecen en recuadros que no solo se alternan en el desarrollo temporal sino que se ubican en los extremos de la pantalla: el espacio del privilegio aparece a la izquierda, los otros a la derecha. El montaje muestra la distancia. Lo de adentro se define por lo de afuera, el muro se resignifica, impide el ingreso de los documentalistas y de nuestra mirada pero también niega estas otras realidades para los de adentro que buscan protegerse de su presunta peligrosidad. Una vez más, el documental es contra-imagen: muestra lo que desde adentro no se quiere ver. La posición intermedia de la cámara, invisibilizada por el recurso pero explícita en otros momentos, es tal vez más crítica que la asociación de la cronista Rojas con los sujetos-frontera que atraviesan el límite; los documentalistas recorren la calle que linda con el muro y con "los vecinos de enfrente", un terreno en apariencia neutro que se vuelve brecha cuando muestra la contradicción.

\section{Viaje/Travelling}

Mundo privado y La ciudad que huye se construyen a partir del movimiento de sus realizadores, inscripto como parte del relato: la cronista que llega a los barrios, los documentalistas que rodean sus muros. La lógica del viaje coincide con la asociación entre el barrio cerrado y el tópico de la isla que establecen Degoutin y Wagon en la ficción: un mundo de difícil acceso y diferente del lugar de origen de los viajeros que puede tomar la forma de una utopía, una trampa o una prisión. La isla es, también, uno de los lugares más visitados por los viajeros literarios desde Odiseo en adelante; un lugar no solo diferente sino lo suficientemente distante para que el trayecto se haga interesante.

El texto de Patricia Rojas recupera para la crónica la estructura del relato de viajes: salir para volver enriquecido, en este caso por la información. No son géneros tan distantes: los une un tipo de pacto no ficcional, la búsqueda de algo desconocido u oculto, el protagonismo de quien cuenta. Teniendo en cuenta la hibridez de un género que suele encabalgarse entre la literatura y las ciencias sociales, en la crónica pueden leerse dos itinerarios de viaje. En el cuerpo principal del texto, el trayecto de la ciudad a los barrios privados; en las notas al pie, un recorrido por otros textos que abordan el mismo objeto y que 
incluye tanto otros libros de testimonios como noticias de medios de comunicación masiva o de los que circulan en el ámbito de los countries, páginas web y artículos académicos de investigadores reconocidos. Aunque este segundo viaje ocupa un espacio considerable y suma voces autorizadas a las entrevistas a sujetos habitualmente anónimos -complementa la originalidad con la confiabilidad-, el viaje material es la trama central.

Cada uno de los barrios abordados implica una entrada y una salida. Sin embargo, el texto entero se configura como un viaje unitario. En el principio, la evocación de las dos primeras entradas: Dalvian y Nordelta. En el final, la salida del Saint Thomas. Como en el primer ingreso, en esta escena la cronista interactúa con un sujeto-frontera, el guardia de seguridad que expresa su rechazo a este tipo de lugares y comenta que el entrenamiento del personal se limita al manejo de las armas y dura entre siete y catorce días. La salida es doble, Rojas sale físicamente del espacio y cuestiona su idealización a través del comentario del guardia que, como es característico del género, la cronista usa para sostener un argumento propio: la utopía de la seguridad, valor principal y en apariencia incuestionable del espacio privatizado, se revela falsa. Entre la entrada y la salida, el recorrido por las voces que habitan un espacio segmentado en barrios y en zonas geográficas que se agrupan de manera discontinua: Pilar, Berazategui, Tigre, otra vez Pilar y Berazategui, Pilar, Moreno, Canning, Campana. El itinerario responde más a la lógica de las historias que a la organización espacial. Sin embargo, el texto toma la forma de un viaje que tampoco es lineal porque consiste en las idas y vueltas entre la Ciudad de Buenos Aires y cada uno de los barrios situados en su periferia y vinculados a ella por la red de rutas mucho más que entre sí o con los otros espacios suburbanos.

El mapa que trazan esos recorridos señala uno de los rasgos principales de los barrios privados: estratégicamente lejos del centro pero conectados con él en una forma que significativamente Svampa (2006) define como red o archipiélago -otra vez la isla-. Las rutas de acceso, sin embargo, se vuelven escenario de la peripecia narrativa en la medida en que, si bien sirven a los habitantes para acceder a sus trabajos o a los servicios que ofrece la ciudad, resultan trabajosos para una cronista que no se mueve en auto como ellos. Los inconvenientes del viaje no solo cubren el espacio narrativo entre uno y otro espacio, entre una y otra historia, sino que caracterizan la relación de estos barrios con su contexto y la posición de la cronista que los conecta.

Es especialmente significativo el viaje de ida y vuelta a Nordelta, ciudad privada de la zona norte del conurbano que fue pensada, justamente, como una utopía urbana capaz de brindar a la vez la tranquilidad de lo distante del centro sin perder ninguna de sus comodidades. Cuando el que viaja no pertenece, sin embargo, el viaje es odisea. "Salimos 13.10 de avenida Corrientes 930 (la parada es un banco de madera: no hay cartel ni nada). El pequeño colectivo arranca y frena hasta llegar a Paseo Colón. Frena un montón. Veinte minutos después llevamos a Lavalle al 200” (Rojas, 2006: 101). Los 
pormenores dan cuenta del esfuerzo del trayecto característico del relato de viaje y de la exclusividad que implica la parada sin señalizar, para iniciados. Otro rasgo propio del relato de viaje es que se vuelve guía, experiencia replicable para los valientes interesados. La salida del mismo espacio refuerza este último rasgo. El ómnibus en que llegó la cronista, que pertenece al barrio y se encarga de conectarlo con la ciudad, deja de pasar a las 8 de la noche, no está prevista la visita de los "extranjeros", al menos no de los que carecen de movilidad propia, lo que bien podría funcionar como diferenciación de clase. La solución, en cambio, caracteriza el lugar de Rojas que termina por abandonar el lugar en una combi destinada a los periodistas que cubrían el recital de Diego Torres para vecinos de Nordelta y que ella también había ido a ver como parte de la investigación. Es decir, a pesar del intento por participar de las prácticas del lugar, de experimentar el espacio, sale como lo que es, periodista, externa. Ese rasgo reaparece en casi todos los recorridos: la combinación de transportes públicos a los que obliga la distancia y la condición que la asimila a los otros sujetos con los que comparte pasaje, como el remís que usa para llegar a El carmel, de la misma empresa que suele transportar a las empleadas domésticas.

El viaje es una forma de estratificación social. Así como la frontera que servía para organizar el texto se volvía objeto de indagación, el viaje es estructura narrativa, marco y objeto de reflexión en las entrevistas. Uno de los chicos del country Banco Provincia comenta: "Un viaje en tren te actualiza" (Rojas, 2006: 279). A continuación, como para ilustrar esa afirmación, la cronista relata su viaje en tren de Once a Moreno, donde se ubica el country. Hay más detalles incluso que en el viaje a Nordelta, desde el choripán que no se anima a comer en la estación "como experiencia antropológica” (Rojas, 2006: 280) hasta la descripción de todas las estaciones cuyo tono la coloca como extranjera a estos otros espacios periféricos. El lugar de intermediaria no permanece estático, la doble marca de extranjería -en el barrio cerrado o en el tren- a veces se desliza hacia una compenetración con los sujetos de su investigación. Una cosa es participar: comer lo que come Mailén en La Peregrina, ver a Diego Torres en Nordelta, participar de una reunión de vecinos que discuten el destino de la basura en El Carmencito, ir a Creamfields con un grupo de adolescentes o a ver Cara de queso (la película de Ariel Winograd sobre adolescentes en un country) con otro. Otra cosa es mimetizarse y empezar a ver el transporte público que la lleva a Moreno con la extrañeza y el desdén que usaban los adolescentes de Nordelta para referirse a otro tren de características similares: "No es muy normal que lo use la gente medianamente bien, económicamente” (Rojas, 2006: 109-110). El lugar intermedio nunca es neutral; no lo es en la calle que recorren los documentalistas de La ciudad que huye ni lo es para esta cronista que alterna entre el rechazo ideológico y la fascinación, una mirada ambigua que también marca al género testimonial aunque, fiel a su objeto predilecto, suela recaer sobre el sujeto popular más que sobre los privilegiados. 
Desde su título, La ciudad que huye debería componer un viaje. La distancia permanece, sin embargo, invisible a la cámara. No hay trayecto hacia las urbanizaciones privadas que solo se ven en el momento de la llegada. El viaje cobra, en cambio, otra forma. En primer lugar, en el nombre con el que el cine designa el recorrido de la cámara por un espacio en un solo plano que se extiende: el travelling es el principio constructivo que el documental usa para dimensionar la presencia del muro. La cámara, presumiblemente ubicada en un auto que avanza por la ruta o la calle que bordea el barrio cerrado, capta el límite como única cara visible de esos espacios inaccesibles. El primero de estos planos aparece inmediatamente después de la primera negación del acceso: la existencia del muro remplaza y justifica la ausencia de representación del interior. Más adelante aparece la reja del Tigre Joven en contraposición con "los vecinos de enfrente" y el muro de Las Palmas que arranca en un pequeño recuadro a la izquierda del fondo negro de la pantalla pero que crece a medida que la cámara lo recorre. El travelling, el viaje de la cámara alrededor de los barrios, es la forma de darles existencia en la representación.

Las últimas dos representaciones del muro introducen diferencias. En el segmento que corresponde a Miraflores, las fronteras se multiplican, ya no se trata del límite particular de este barrio sino de una descripción que hace la voz en off de las diferentes formas que puede tomar - muro, reja, enredadera- y que se ilustran en una serie de recuadros que forman una retícula que segmenta la pantalla. El viaje ya no es de la cámara sino de la mirada del espectador que recorre el catálogo de posibilidades. La última imagen del muro es la más significativa en la medida que cierra el documental y, de alguna manera, también el sentido de todo el recorrido. En Isla del Sol, por primera vez, la imagen del muro incluye la presencia humana que antes aparecía solo enfrente o en su remplazo -los "vecinos", los guardias-; no es la cámara la que avanza sobre él sino que es un grupo de niños el que se desplaza bordeándolo. No solo están del lado de afuera, del lado de la cámara, sino que el guardapolvo que visten debería leerse como una marca de clase, pues los hijos de los barrios privados no van a la escuela pública a la que corresponde esa vestimenta. El muro, en el último plano, es exclusión: mientras una leyenda cuantifica el crecimiento del número de urbanizaciones cerradas, la imagen del viaje de los chicos de afuera se achica y se torna borrosa, se acerca a la invisibilidad que buscan los de adentro.

Intercalado con ese viaje fílmico, el documental incluye otro recorrido por mapas y planos. Primero, el mapa antiguo en el que se anima el crecimiento de la cuadrícula urbana mientras se relata y se contabiliza el crecimiento asociado a políticas de Estado. El sonido del tren que acompaña la imagen en la que se visualiza su recorrido es parte de la "huida": el crecimiento que arranca en la ciudad de la mano del Estado sale de ella mientras este abandona la voluntad política de moldear el espacio que queda en manos privadas. La interrupción del sonido del tren que se escuchaba antes señala ese abandono estatal que también afecta a la red ferroviaria que fuera objeto favorito de los discursos del progreso argentino desde el siglo XIX. Al espacio ideal del barrio cerrado no le corresponde, sin embargo, solo la 
representación ideal que dibuja rutas y superficies ocupadas sino que cada uno de los barrios que segmentan el documental es presentado por un zoom en el mapa satelital de la zona. La ciudad que huye se basa en una economía de la representación que potencia la expresividad de cada imagen, lo que hace posible condensar todo su contenido en menos de cinco minutos de duración. El mapa satelital no es solo la imagen que reemplaza lo que la cámara no puede captar, es también la prueba de que incluso quienes se resguardan detrás de un muro que garantiza discreción además de seguridad están expuestos a las mismas tecnologías de vigilancia que los de afuera. La reutilización de estas imágenes es el reverso del uso de las imágenes de seguridad en el documental On the Safe Side que analizaba Muñoz Aunión (2013). Martel no recupera la imagen del afuera desde el country sino la inversa: el country visto desde arriba, el único afuera capaz de saltar el muro. Aunque la mirada vaya en dirección contraria, las prácticas productoras de imágenes son las mismas: es el mismo mundo el que genera la privatización del espacio residencial con sus cámaras de seguridad y la exposición constante de las imágenes de lo privado.

El documental, como la crónica, es un género híbrido en tanto admite la inclusión de materiales de diferentes procedencias. Las imágenes de la cámara conviven con las tomadas por satélite, las producidas para el film con las tomadas de otras fuentes e, incluso, las producidas por otros medios como el plano. Mientras la voz en off se hace cargo de un discurso histórico que cuenta el origen y el auge de esta forma de ocupación del espacio entre las décadas de 1970 y 1990, un plano animado muestra primero ese “archipiélago" formado por la Ciudad de Buenos Aires, las autopistas y las urbanizaciones que se ubican a lo largo de ellas para luego descomponerlo y reorganizarlo para armar un solo bloque de espacios privatizados que permite comparar la superficie total que ocupan con la de la ciudad. Este plano es el reverso y la continuación del primero; en este se completa la historia de los emprendimientos privados que empiezan cuando el Estado se retira; el mapa satelital reemplaza al plano en sepia, ya no hay sonido de tren sino líneas amarillas que dibujan las nuevas autopistas sobre el plano. Esta inclusión implica llevar al plano visual el lenguaje histórico y estadístico que recorre todo el documental, desde la inclusión de un contador de metros que aparece cuando empieza el relato y sigue corriendo en el extremo inferior izquierdo y otro que en la segunda mitad del documental cuenta metros de muro y se ubica en la esquina superior derecha. Esos números que aumentan sin cesar configuran una suerte de sub-trama que acompaña el desarrollo del documental hasta que la inclusión del plano comparativo de superficies vuelve sobre esa información para cerrar el documental con los otros números que cuantifican la cantidad de urbanizaciones cerradas en la Provincia de Buenos Aires. Lo estadístico coloniza la pantalla. En el último cuadro, al mismo tiempo que se reduce la imagen de los chicos en guardapolvo que recorren el muro, cobran protagonismo los números que siguen corriendo. El final condensa significados, los explícitos de la estadística y los implícitos en la imagen, y pone de manifiesto los recursos del género: el cruce de 
Mercedes Alonso. Periferias genéricas...

lenguajes que ubica en un mismo momento el máximo de abstracción numérica y de focalización en la dimensión humana.

\section{Conclusión}

La ciudad que huye y Mundo privado podrían oponerse como perspectivas inversas. Mientras el documental de Lucrecia Martel enfoca lo que queda afuera del barrio privado -la cara externa del muro, el personal de seguridad, los vecinos, los propios realizadores-, la crónica de Patricia Rojas penetra el mundo oculto detrás de sus fronteras. Los dos ponen en escena el problema de los límites y la accesibilidad. Martel convierte el contratiempo en contendido del documental -la primera escena cuenta justamente la negativa del ingreso de la cámara- y Rojas convierte el viaje en conexión entre espacios y comentario sobre ellos y sobre su propia tarea -la cronista como viajera-.

La diferencia se lee en los títulos. Mientras Rojas pone en el centro lo "privado" como un objeto que va a ser revelado, Martel ve, desde afuera, la ciudad que se aleja. Como todo en el documental, lo sentidos del título son múltiples. Es, en primer lugar, la inversión de la utopía del barrio privado como huida de lo urbano, solo que ya no serían las personas las que abandonan la ciudad sino el espacio mismo el que se desplaza. Segunda ambigüedad, el movimiento corresponde a los barrios cerrados que escapan hacia un lugar mejor o más seguro desplazándose a lo largo de esas rutas que se ven en el plano animado o bien corresponde a la gran ciudad a la que las personas ven alejarse mientras se desplazan a estos nuevos entornos. Lo "privado" de la crónica de Rojas es también, al menos, doble: privados son los espacios que constituyen el tema de la crónica y también los testimonios que la nutren, una elección metodológica y formal entre las muchas posibles del género no-ficcional. El segundo sentido refuerza la distancia con el documental: la cronista logra el acceso al interior del barrio y a la subjetividad de sus habitantes.

Los vínculos con la realidad que postulan tanto los géneros no ficcionales de la literatura como el documental, sin embargo, obligan a la incorporación de otros elementos. Allí están las notas al pie de Rojas que refuerzan la credibilidad de las voces testimoniales y del trabajo periodístico y también, como en Martel, la incorporación de números y estadísticas en la presentación de cada uno de los barrios. Los dos géneros tienden a la hibridez. Pareciera ser que los testimonios privados que recoge Rojas, los primerísimos planos de Martel sobre los guardias o los muros, la experiencia del espacio en los dos casos no alcanzan a dimensionar el fenómeno. El documental y la crónica dan cuenta del mundo a través del contrapunto entre lo particular y las generalizaciones y contextualizaciones que proveen los discursos de la historia, la sociología o la estadística.

Particularidad del género, o uno de sus límites, esa hibridación sostiene el modo en que los dos textos se hacen cargo de una realidad que, en el momento en que fueron producidos, parecía inundar una 
multiplicidad de discursos sociales. Aunque no eran un fenómeno nuevo, en el principio del siglo XXI la atención mediática, académica y de la literatura y el cine convergía sobre los barrios cerrados. Parecía inevitable tomar posición. La particularidad de Mundo privado y La ciudad que huye es que enmarcan el abordaje en géneros usualmente dedicados a representar lo marginal, lo subalterno, lo popular y, a partir de ese cambio de objeto, se permiten una desviación frente a un mandato ético que atraviesa la realización documental y testimonial. Para el primero lo señalan sus principales teóricos. Todo documental debe preguntarse qué hacer con la gente, con sus voces y su representación, dice Bill Nichols (1997), mientras que Carl Plantinga (2011) establece un deber de cuidado del documentalista frente a los sujetos que filma. Rossana Nofal (2002) señala un problema ético similar para los géneros testimoniales en los que el cronista se apropia de un relato oral en función de su propia interpretación de la realidad. El cambio en el foco de atención que pasa de los marginales a las clases dominantes parece quebrar ese mandato. El juicio de valor es más explícito y terminante cuando la relación entre el objeto y las voces que conducen los relatos se invierte; cuando el otro es el privilegiado.

Probablemente sea la única transformación de los marcos genéricos pero es significativa en tanto la asociación entre otredad y marginalidad y el imperativo de representación como práctica política constituye un lugar común muy afianzado. Patricia Rojas termina su crónica desde la voz del subalterno, el guardia de seguridad que rechaza el modelo y señala sus fallas. Mimetizarse con esa voz marca su distancia social con los otros sujetos entrevistados, los privilegiados, y la distancia crítica con sus voces. En el documental de Martel no hay testimonios y escasean las imágenes humanas. Los guardias de seguridad ni siquiera son percibidos como personas: sus cuerpos recortados, tomados en fragmentos, a veces solamente como voces inmateriales, son más parte de la frontera que sujetos con un carácter ambiguo, a la vez subalternos pero defensores del privilegio. El contraste es con los "vecinos de enfrente" y los chicos del final que sí son captados de manera integral y en su dimensión humana. Mientras el documental enjuicia el estilo de vida de los privilegiados invisibles, expone su contracara en imágenes. La dimensión ética se distribuye de manera desigual entre las clases sociales que pueblan el espacio: el juicio recae sobre los que viven adentro mientras -y gracias a que- se pretende sostener la solidaridad con los de afuera. 


\section{Corpus}

Rojas, Patricia (2007). Mundo privado. Historias de vida en countries, barrios privados y ciudades cerradas. Buenos Aires: Planeta/Seix Barral.

Martel, Lucrecia (2006). La ciudad que huye. Argentina: Estudio Fantasma.

\section{Bibliografía}

Amar Sánchez, Ana María (2008). El relato de los hechos: Rodolfo Walsh: testimonio y escritura. Buenos Aires: de la Flor.

Andermann, Jens (2015). Nuevo cine argentino. Buenos Aires: Paidós.

Bernabé, Mónica (2006). “Prólogo”. María Sonia Cristoff (comp.). Idea crónica. Literatura de no ficción iberoamericana. Rosario: Beatriz Viterbo-Fundación TyPA.

Degoutin, Stéphane y Wagon, Gwenola. “Built metaphors: gated communities and fiction”.

Duchesne Winter, Juan (1992). Narraciones de testimonio en América Latina. Cinco estudios. Río Piedras: Ed. de la Universidad de Puerto Rico.

Ford, Aníbal (1987). "Walsh: la reconstrucción de los hechos". Desde la orilla de la ciencia. Ensayos sobre identidad, cultura y territorio. Buenos Aires: Puntosur.

Muñoz Aunión, Marta. "La recompensa del muro o la insegura proliferación del 'barrio cerrado'. Reflexiones en torno a 'La zona' y 'On the safe side”. Kamchatka. Revista de análisis cultural 2 (2013): 57-83. DOI: 10.7203/KAM.2.2319.

Nichols, Bill (1997). La representación de la realidad. Cuestiones y conceptos sobre el documental. Buenos Aires: Paidós.

Nofal, Rossana (2002). La escritura testimonial en América Latina: Los imaginarios revolucionarios del Sur: 1970-1990. Tucumán: Instituto Interdisciplinario de Estudios Latinoamericanos; FFyL; Universidad Nacional de Tucumán.

Plantinga, Carl. “Documental”. Revista Cine Documental3 (2011).

Svampa, Maristella (2004). La brecha urbana. Countries y barrios privados. Buenos Aires: Capital Intelectual. 